\title{
Projected changes in mean and interannual variability of surface water over continental China
}

\author{
LENG GuoYong ${ }^{1,4^{*}}$, TANG QiuHong $^{1}$, HUANG MaoYi ${ }^{2}$, HONG Yang ${ }^{3}$ \& Leung L RUBY ${ }^{2}$ \\ ${ }^{1}$ Institute of Geographic Sciences and Natural Resources Research, Chinese Academy of Sciences, Beijing 100101, China; \\ ${ }^{2}$ Atmospheric Sciences and Global Change Division, Pacific Northwest National Laboratory, Richland, WA 99352, USA; \\ ${ }^{3}$ School of Civil Engineering and Environmental Sciences, University of Oklahoma, Norman 73019, USA; \\ ${ }^{4}$ University of Chinese Academy of Sciences, Beijing 100049, China
}

Received March 28, 2014; accepted June 30, 2014; published online December 8, 2014

\begin{abstract}
Five General Circulation Model (GCM) climate projections under the RCP8.5 emission scenario were used to drive the Variable Infiltration Capacity (VIC) hydrologic model to investigate the impacts of climate change on hydrologic cycle over continental China in the 21st century. The bias-corrected climatic variables were generated for the Fifth Assessment Report of the Intergovernmental Panel on Climate Change (IPCC AR5) by the Inter-Sectoral Impact Model Intercomparison Project (ISIMIP). Results showed much larger fractional changes of annual mean Evapotranspiration (ET) per unit warming than the corresponding fractional changes of Precipitation (P) per unit warming across the country, especially for South China, which led to a notable decrease of surface water variability (P-E). Specifically, negative trends for annual mean runoff up to $-0.33 \% /$ year and soil moisture trends varying between $-0.02 \%$ to $-0.13 \% /$ year were found for most river basins across China. Coincidentally, interannual variability for both runoff and soil moisture exhibited significant positive trends for almost all river basins across China, implying an increase in extremes relative to the mean conditions. Noticeably, the largest positive trends for runoff variability and soil moisture variability, which were up to $0.41 \%$ year and $0.90 \% / y e a r$, both occurred in Southwest China. In addition to the regional contrast, intra-seasonal variation was also large for the runoff mean and runoff variability changes, but small for the soil moisture mean and variability changes. Our results suggest that future climate change could further exacerbate existing water-related risks (e.g., floods and droughts) across China as indicated by the marked decrease of surface water amounts combined with a steady increase of interannual variability throughout the 21 st century. This study highlights the regional contrast and intra-seasonal variations for the projected hydrologic changes and could provide a multi-scale guidance for assessing effective adaptation strategies for China on a river basin, regional, or as a whole.
\end{abstract}

climate change, surface water, interannual variability, China

Citation: Leng G Y, Tang Q H, Huang M Y, et al. 2015. Projected changes in mean and interannual variability of surface water over continental China. Science China: Earth Sciences, 58: 739-754, doi: 10.1007/s11430-014-4987-0

Global warming is projected to increase rainfall variability (O’Gorman and Schneider, 2009) and substantially intensify the global water cycle (Durack, 2012), with notable effects on the water availability for ecosystems and agriculture (Arnell, 2003). Most Asian countries are facing challenges

*Corresponding author (email: lenggy.11b@igsnrr.ac.cn) in adapting to social and environmental problems associated with climate changes (Zhai et al., 2005; Fujibe et al., 2006; Yao et al., 2008; Kranz et al., 2010). China is one of the most vulnerable countries around the world to future climate changes with water being one of the sectors most directly affected (Piao et al., 2010). Such vulnerabilities are further exacerbated by its incomplete or not-so-well-designed water infrastructure. A robust response to future climate change is 
to develop effective adaptation strategies and actions based on sound management and knowledge of the water resource infrastructure and scientific basis for how climate changes may influence the hydrologic systems.

Motivated by the above needs, several studies have focused on the likely changes of hydrology and water resources in some major river basins over North China where water related issues have already emerged as a serious problem (Li et al., 2008; Xu et al., 2009; Li et al., 2010; Yang et al., 2012). For example, using an improved XAJ model, Li et al. (2008) projected an approximately 5\% decrease in runoff for the headwater region of the Yellow River. Li et al. (2010) predicted a $-19.8 \%$ to $37.0 \%$ change for runoff and $-5.5 \%$ to $17.2 \%$ change for soil moisture in Heihe watershed by 2010-2039. The frequent occurrences of extreme hydrological events (e.g., flooding and droughts) in South China have also attracted more attentions recently (Jiang et al., 2007; Qiu, 2010; Xu et al., 2012; Zeng et al., 2012; Zhang et al., 2013). For example, Zeng et al. (2012) showed that annual river discharges in the Yangtze River Basin have no obvious trends based on global climate model ECHAM5/MPI-OM. Using the calibrated VIC model, Zhang et al. (2013) showed that the annual runoff will likely increase across the Huaihe River Basin with exacerbated regional flooding/shortage. However, the climate change impacts on the water sector for the country as a whole has rare been studied (Guo et al., 2002; Wang et al., 2012), which has hampered a comprehensive assessment over different regions, some of which are connected by projects such as the South-North Water Transfer. Using a monthly water balance model applied over China, Guo et al. (2002) suggested that the semi-dry and semi-humid regions in North China are more sensitive to climate changes than those river basins in the humid regions of South China. Recently, Wang et al. (2012) assessed the hydrologic response to climate changes over China using calibrated VIC model based on the PRECIS climate model system, and projected an increase of total runoff by approximately $3 \%-10 \%$ by the 2050s relative to the baseline 1961-1990. However, without an explicit evaluation of suitability of the specific General Circulation Model (GCM) climate scenario, single or two GCMs are still used at the regional scale (Zeng et al., 2012) and continental scale (Guo et al., 2002; Wang et al., 2012) despite evidence from numerous studies that an over-reliance on a single GCM could lead to an inappropriate projection of hydrologic responses to climate changes. More importantly, due to the coarse resolution of GCM climate data, hypothetical scenarios or delta change factor approach was adopted in most previous studies in deriving future climate change scenarios (Jiang et al., 2007; Guo et al., 2002; Li et al., 2010; Dan et al., 2012). By this approach, changes in monthly climatology were preserved whereas changes in climate variability (e.g., increased precipitation variability) were not well represented (Portmann et al., 2013) with potential effects on the projected hydrological extremes.
Most studies focus mainly on the annual mean changes of water cycle component, especially in total runoff. In many instances, however, the increased variability and resulting extreme conditions could even be more difficult than mean condition changes for the society to adapt to (Katz and Brown, 1992; Rahmstorf and Coumou, 2011) and have been explored in various regional climate simulation studies as a measure of systematic variation from one year to the next (Räisänen, 2002; Schar et al., 2004; Giorgi et al., 2004). Hence, it is very important to elucidate the spatial and temporal patterns of this variability of projected hydrologic responses to climate changes since changes in hydrologic variability have been reported to be as important as changes in the mean state especially for agriculture, ecosystems, and water resources management (Easterling et al., 2000a, 2000b).

The primary goal of this study is to examine the projected changes of surface water across China using climatic variables from the Fifth Assessment Report of the Intergovernmental Panel on Climate Change (IPCC AR5) to provide up-to-date knowledge of how water resources distributions in China might evolve in the future. The novelty of this study is: (1) Multi-model ensemble mean approach based on climate scenarios from Coupled Model Intercomparison Project Phase 5 (CMIP5) archive and calibrated hydrological model were adopted to provide updated investigation on the impact of climate change for ten major river basins over China. (2) The impact of climate variability was accounted for by applying the bias-corrected daily climate model output, which was developed within the Inter-Sectoral Impact Model Intercomparison Project (ISI-MIP) (Hempel et al., 2013). (3) Not only the changes in the mean of water cycle (Precipitation, evaportranspiration, runoff, and soil moisture) but also the interannual and seasonal variability (30-year timescales) was considered to comprehensively characterize the hydrological response to climate change. (4) Unlike most previous studies that considered specific future time periods, we examine consecutive 30 years periods throughout the 21st century, which allows us to investigate the multidecadal variability and trends of hydrologic changes. Through this analysis, we aim to identify regions with high risks and provide guidance for the design of effective climate change adaptation strategies and actions, especially on how to optimize human water use (e.g., domestic, industry, and agriculture irrigation) in the future.

\section{Data and methodology}

\subsection{Bias-corrected climate dataset}

The fast-track of the Inter-Sectoral Impact Model Intercomparison Project (ISI-MIP) aims to quantify the uncertainty in projecting climate change impacts on water, biomes, and agriculture using a minimal setting that spans uncertainties in climate models, climate scenarios, and impact models and sectors (Hempel et al., 2013). As a compromise, 
only 5 GCMs driven by multiple Representative Concentration Pathway (RCP) scenarios were bias-corrected to provide climate change forcing for impact models. For our analysis, we used the bias-corrected climate data from all 5 GCMs (HadGEM2-ES, GFDL-ESM2M, IPSL-CM5A-LR, MIROCESM-CHEM, and NorESM1-M) provided by ISI-MIP. The atmospheric data, including precipitation, air temperature, wind speed, surface radiations, air pressure, and specific humidity, were provided at $0.5^{\circ} \times 0.5^{\circ}$ spatial resolution at daily time step from 1950 to 2099 (Hagemann et al., 2013). The most conservative scenario RCP8.5 in which the anthropogenic radiative forcing equals $8.5 \mathrm{~W} \mathrm{~m}^{-2}$ by 2100 was selected, given that the observed $\mathrm{CO}_{2}$ emissions in the period of 2000 to 2006 are larger than those estimated by models (Canadell et al., 2007). Also, at the time scale of a century up to 2100 , the signal to noise ratio for this extreme scenario is expected to be more significant compared to the other three RCP scenarios.

\subsection{Variable Infiltration Capacity model and setup}

The Variable Infiltration Capacity (VIC) model (Liang et al., 1994, 1996), a semi-distributed macroscale hydrological model, was applied in this study to partition the incoming precipitation into runoff, ET, and soil moisture. The model is characterized by representing subgrid variability in precipitation, vegetation classes, soil moisture storage capacity, and topography. More details can be found elsewhere (Liang et al., 1994, 1996; Nijssen et al., 1997). The VIC model simulates both the water and energy budgets within the grid cell and has been widely used to assess the impact of climate change on water resources and hydrology in many studies (Hamlet and Lettenmaier, 1999; Christensen et al., 2004; Maurer, 2007; Hayhoe et al., 2007; Wang et al., 2012). Land surface characteristics such as soil, vegetation, and elevation for this study were obtained from Nijssen et al. (2001). The calibrated VIC parameters were obtained from Zhang et al. (2014) in which the infiltration parameter $b$, the second and third soil layer depths $(d 2, d 3)$, and the three parameters in baseflow scheme $(D m, D s, W s)$ were calibrated for the ten river basins (Figure 1) over China to reproduce the long-term monthly stream flow observations using 15 hydrological stations and validated against the observed soil moisture using 43 stations obtained from the Global Soil Moisture Data Bank (Robock et al., 2000). The spatial resolution of the calibrated parameters, which was $0.25^{\circ}$, was aggregated into $0.5^{\circ}$ for use in our study. This study only assessed the climate change impacts on water resources without considering the dynamical effects of human activities. Assuming constant of model parameters, this study shows the hydrologic response only to climate change/variability projected by GCMs. By using the above bias-corrected climate data, time series of hydrologic terms from VIC were produced for the period 1950-2099. We excluded the first 20-year results as model spin up to eliminate the impact of initial conditions and started our analysis from 1971 to 2099.

\subsection{Analysis measures}

Changes in mean and coefficient of variation $(\mathrm{CV})$ as a measure of interannual variability were used to analyze the impacts of future climate change on water balance terms over China. Here, changes are defined as the relative differences between each future 30 years period in the time series of 1971-2099 and the reference period of 1971-2000, expressed as a percentage of the 1971-2000 value to allow a consistent inter-comparison (Tang and Lettenmaier, 2012) and investigation of multidecadal variability and trends of hydrologic changes. A running average of 30 years was

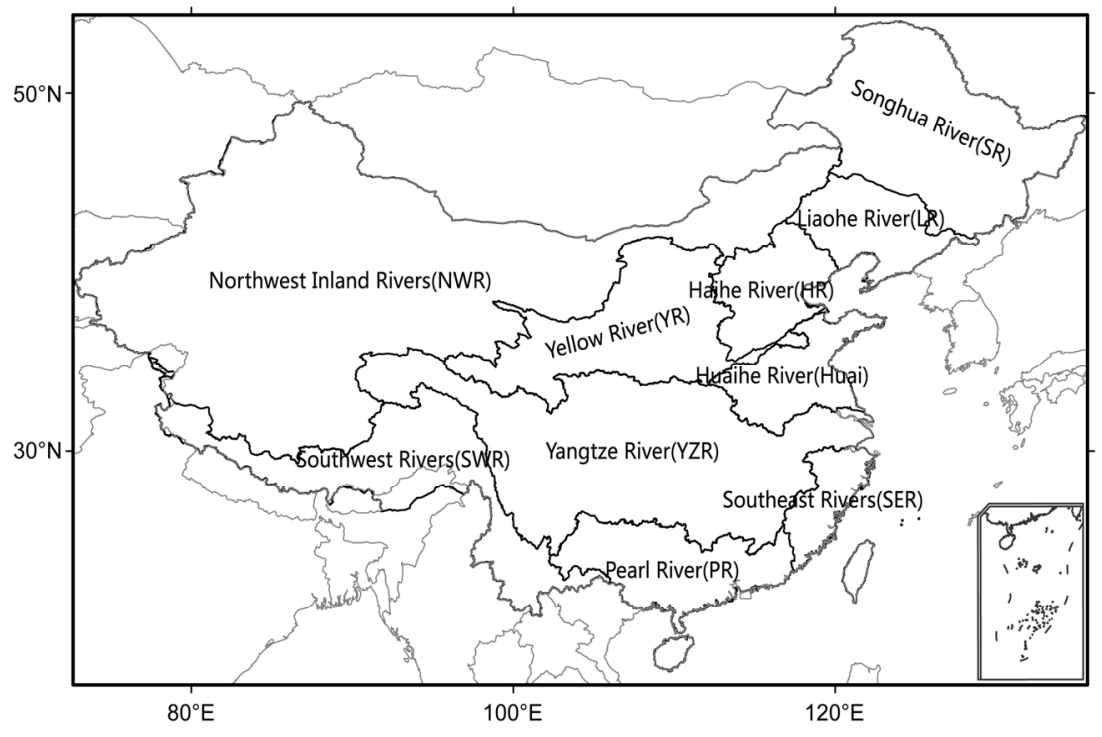

Figure 1 The modeling domain and ten river basins in the study area. 
calculated for each year with the 30 years period centering at that year. $\mathrm{CV}$ is defined as the standard deviation normalized by the 30 years average, similar to that used in Räisänen (2002). CV is also calculated for each 30 years period following the way the running average was calculated. Figure 1 shows the modeling domain and the locations of the ten river basins in the study area, which were grouped into North China and South China based on the existing spatial structure of water resource distribution across China. That is, North China includes the Songhua River (SR), Liaohe River (LR), Haihe River (HR), Northwest Inland Rivers (NWR), and Yellow River (YR), whereas South China includes theYangtze River (YZR), Huai River (Huai), Southwest Rivers (SWR), Southeast Rivers (SER), and Pearl River (PR). In addition, the regional mean change was calculated by averaging VIC inputs/outputs over the individual grid cells within each specific region for each GCM scenario. In order to reduce the uncertainties arising from GCMs, the ensemble average change was calculated by averaging over the individual changes from VIC for all GCM scenarios. The superiority of the multi-model ensemble method to any individual GCM has been well demonstrated in assessing climate change impacts in both global and regional studies (Reichler and Kim, 2008; Pierce et al., 2009). Adopting the multi-model ensemble method could also largely cause the cancellation of offsetting errors in the individual GCMs and has been recommended in both global and regional studies (Pierce et al., 2009). Note that extreme events could be eliminated by the multi-model ensemble mean approach. Choosing a suitable GCM projection could be an appropriate alternative, which is associated with huge works on climate model evaluation against observed historical climate data and should therefore be addressed in further studies. Moreover, the results of choosing suitable GCMs or weighting GCM models based on their performance are dependent highly on the evaluation criteria (Mote et al., 2011). Based on these 5 GCMs provided by ISI-MIP, several studies have also demonstrated the value of multimodel ensemble method in quantifying the impacts of climate change/variability on water resource (Wada et al., 2013; Piontek et al., 2014; Elliott et al., 2014; Schewe et al., 2014; Portmann et al., 2013). To compromise, we show the results by either specific GCM or box diagram/error bar associated with multi-GCMs in the following analysis, in order to characterize the extreme event or uncertainty ranges/ magnitudes arising from GCMs.

\section{Results}

\subsection{Hydrologic response to future climate change across continental China}

Figure 2 shows the ensemble average changes in annual mean precipitation $(\mathrm{P})$ and precipitation minus evapotranspiration (P-E) over Continental China for 2010-2039 mi- nus 1971-2000 and 2070-2099 minus 1971-2000. The near future period 2010-2039 was selected because the results could be much helpful for decision making while the far future period 2070-2099 was selected to highlight the largest possible temperature change at the end of the twentyfirst century (Moss et al., 2010; Rogelj et al., 2012). It is found that annual mean $\mathrm{P}$ decreases across the country especially in South China with a decrease larger than $0.8 \mathrm{~mm} \mathrm{~d}^{-1}$ in the latest decades (i.e., 2010-2039). This decrease of annual mean $\mathrm{P}$ combined with increase of ET leads to the overall decrease of $\mathrm{P}-\mathrm{E}$, which is the net flux of water at the land surface across the country as shown in Figure 2(b). By the end of 21st century (i.e., 2070-2099), annual mean P increases across almost all of China, except for the lower reaches of Yangtze River Basin (Figure 2(c)). The greatest change of annual mean $\mathrm{P}$ was found in river basins across northeastern China (e.g., SR, LR, HR), with an increase up to $0.3 \mathrm{~mm} \mathrm{~d}^{-1}$. Relatively small changes of annual mean $\mathrm{P}$ $\left(<0.1 \mathrm{~mm} \mathrm{~d}^{-1}\right)$ were found over the major part of Northwest China. Conversely, P-E was projected to decline across major regions of China (Figure 2(d)), as a consequence of increased evaporative demand in a warming world (Dai, 2013). Specifically, the strongest reductions of annual mean P-E up to $-0.5 \mathrm{~mm} \mathrm{~d}^{-1}$ were found in major areas of South China especially in YRZ and SWR, although the corresponding annual mean $\mathrm{P}$ increases in much of this same area. No evident change of annual mean $\mathrm{P}-\mathrm{E}$ was found over most parts of North China, except for HR and LR and SR where $\mathrm{P}-\mathrm{E}$ became positive and negative respectively.

Figures 3(a) and 4(a) show the fractional change of annual mean $\mathrm{P}$ per unit warming versus the corresponding fractional change of ET per unit warming for China, North China and South China for 2010-2039 minus 1971-2000 and 2070-2099 minus 1971-2000 respectively. It is shown that the long-term inter-model spread in predicted water balance components per unit warming is large with the sign of fractional $\mathrm{P}$ change per unit warming disagreeing among models even when averaged over the whole country. In Figure 3(a), one specific GCM even projected a decrease by $80 \%$ of fractional $\mathrm{P}$ change per unit warming, which potentially contributed to the significant decrease of annual mean $\mathrm{P}$ as predicted by the multi-model ensemble average in Figure 2(a). This suggests that the over-reliance on a single GCM could lead to an inappropriate projection of hydrologic responses to climate change without evaluation of suitability of specific GCM climate scenario and thus multimodel ensemble approach should be encouraged. However, all models agree that the predicted fractional changes of annual mean ET per unit warming are much larger than the corresponding fractional changes of $\mathrm{P}$ per unit warming for North China and South China as well as the whole country (Figure 3(a)). This indicates that, regionally averaged, the increase of precipitation is consumed by the increase of ET in a warming climate so that the residual component of the water balance (i.e., runoff) in the long term is constrained. 

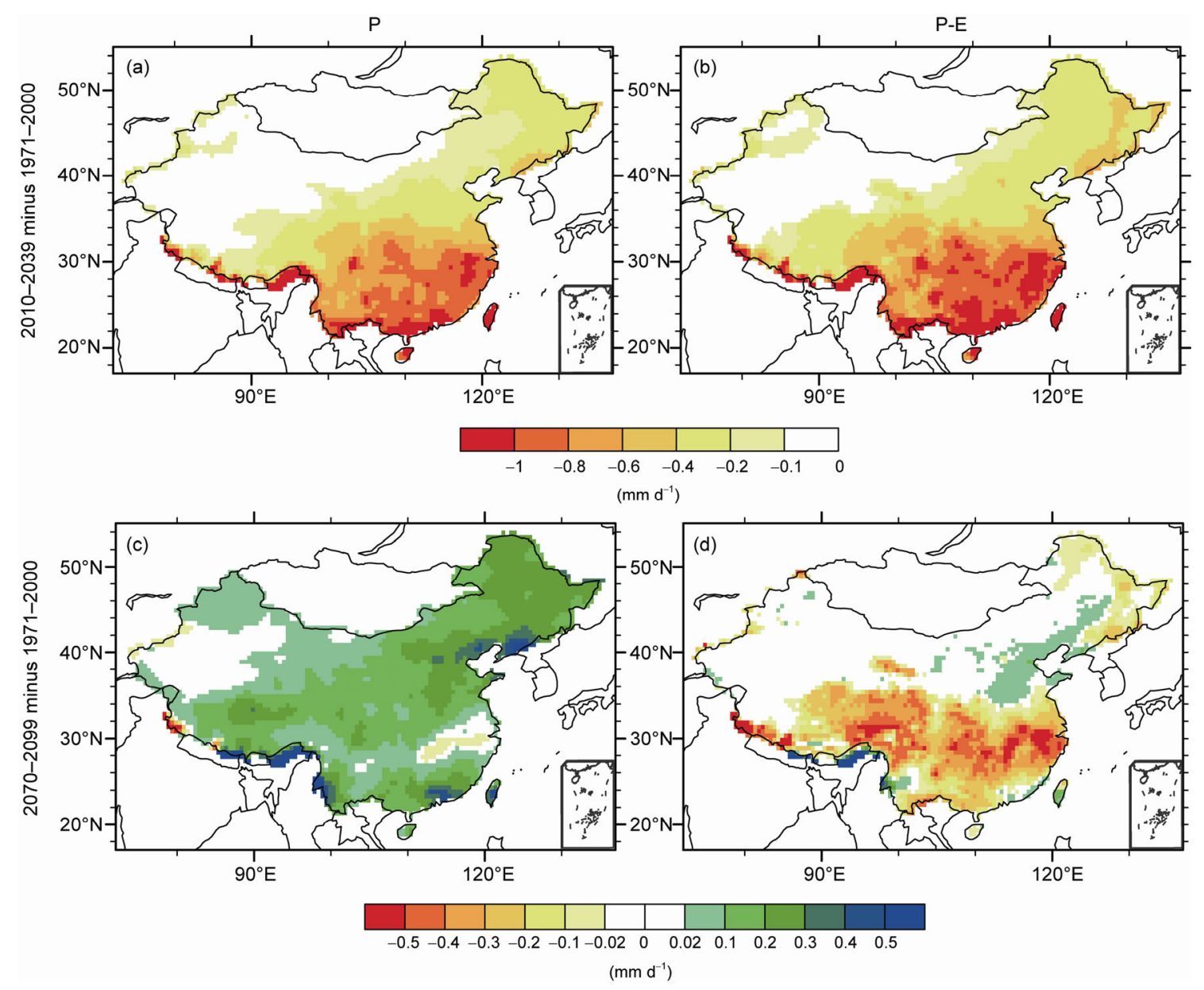

Figure 2 Multi-model ensemble average change in annual mean (a) P and (b) P-E for 2010-2039 minus 1971-2000, and (c) P and (d) P-E for 2070-2099 minus 1971-2000, using the RCP8.5 emissions scenario for the future and the historical forcing for the past.
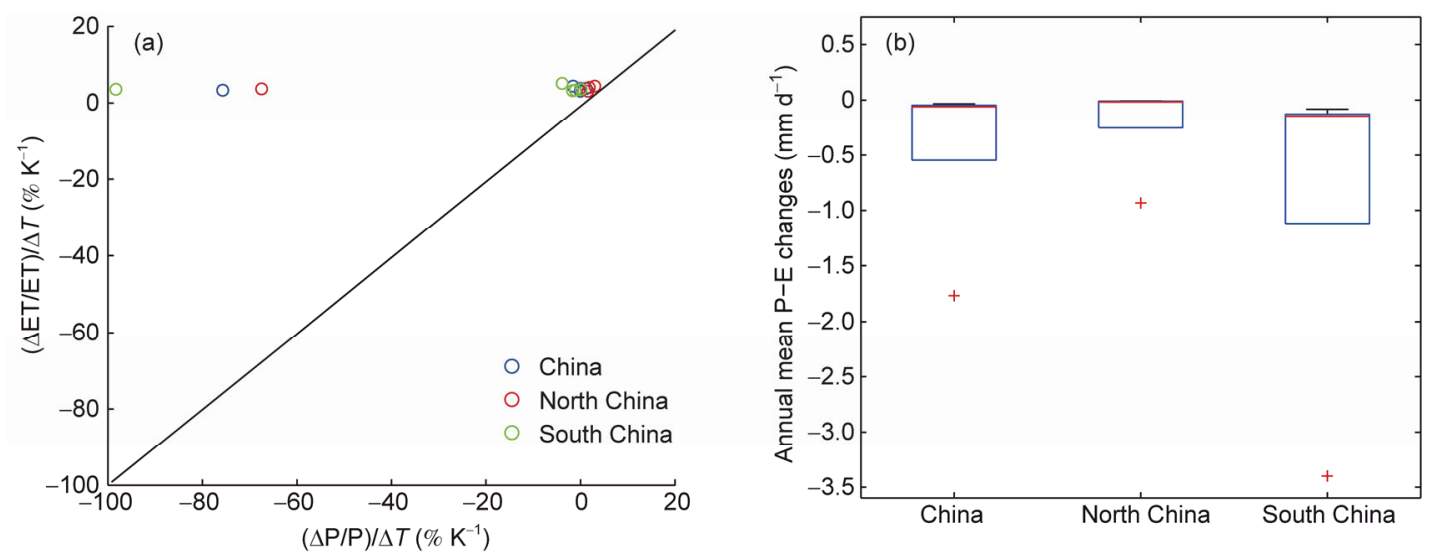

Figure 3 (a) Fractional changes of annual mean P per unit warming versus the corresponding fractional changes of ET per unit warming for China (blue), North China (red) and South China (green) for 2010-2039 minus 1971-2000. Note relative changes for annual mean P and ET were divided by absolute changes in annual mean $T$ respectively. Each open symbol indicates a GCM estimate. (b) Box plots illustrating the annual mean changes of P-E for China, North China and South China. Note that the absolute changes in P-E that represent the available water resource were shown for each region by the 5 GCMs. The box edges illustrate the 25th and 75th percentile, the central mark is the median, and the whiskers mark the 5th and 95th percentiles.

In addition, South China exhibits a much larger fractional increase of ET per unit warming than North China, suggesting that South China will experience larger impacts in the future. The similar results are more evident by the end of 21st century as shown in Figure 4(a). This regional discrepancy is partly because North China is already very dry, so ET 


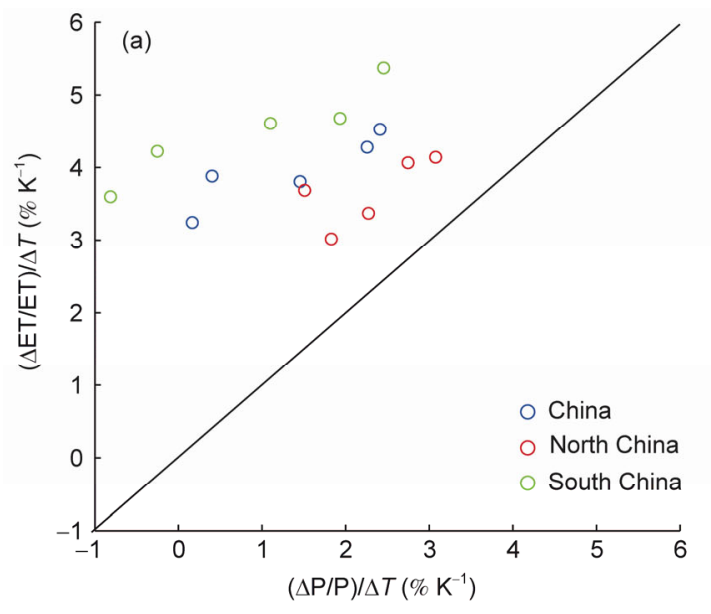

Figure 4 As in Figure 3 but for 2070-2099 minus 1971-2000.

cannot increase by much even if evaporative demand increases. From the multi-model average estimates (Figures 3(b), 4(b)), the changes of surface water availability (i.e., P-E) exhibit obvious regional differences across China. Specifically, for the regional changes in the latest decades, multi-model ensemble mean annual P-E decreased -0.82 $\mathrm{mm} \mathrm{d}^{-1}$ in South China, compared to decrease of $-0.2 \mathrm{~mm} \mathrm{~d}^{-1}$ in North China. By the end of 21st century, a large decrease of P-E up to $-0.24 \mathrm{~mm} \mathrm{~d}^{-1}$ was found for South China, while North China showed little change $\left(-0.04 \mathrm{~mm} \mathrm{~d}^{-1}\right)$.

From the viewpoint of water resource management, it is the seasonal changes of runoff and soil moisture that are critical for agriculture and ecosystem management. Therefore, Figures 5 and 6 show the changes in temperature (T), P, ET, soil moisture, and runoff (hereafter, runoff refers to the combined surface and subsurface runoff) for four seasons averaged over China, North China and South China for 2010-2039 minus 1971-2000 and 2071-2099 minus 19712000 in the form of box and whisker diagrams respectively. In the latest decades, overall increase of median $T$ around $1.5 \mathrm{~K}$ was found across the country (Figure 5). Decrease of median $\mathrm{P}$ in all seasons combined with corresponding increase of ET in a warming climate led to decrease in median soil moisture for all seasons. Relative to other seasons, a larger increase of median ET in summer contributed to the significant decrease of summer runoff for the country as a whole. The significant increase of winter runoff in North China is partly related to a higher fraction of $\mathrm{P}$ falling as rain instead of snow and/or earlier snowmelt in a warmer climate, which contributes to the overall increase in runoff for the whole country in winter. By the end of 21 st century (Figure 6), the median $\mathrm{P}$ increases in all seasons with the largest increase in summer and relatively small increase in winter and autumn when averaged over the country. The seasonal change pattern of ET generally matches that of the $\mathrm{P}$ changes. However, a major portion of $\mathrm{P}$ was evaporated in spring and summer. These combined changes of $\mathrm{P}$ and ET translate into increase in the median in runoff for autumn

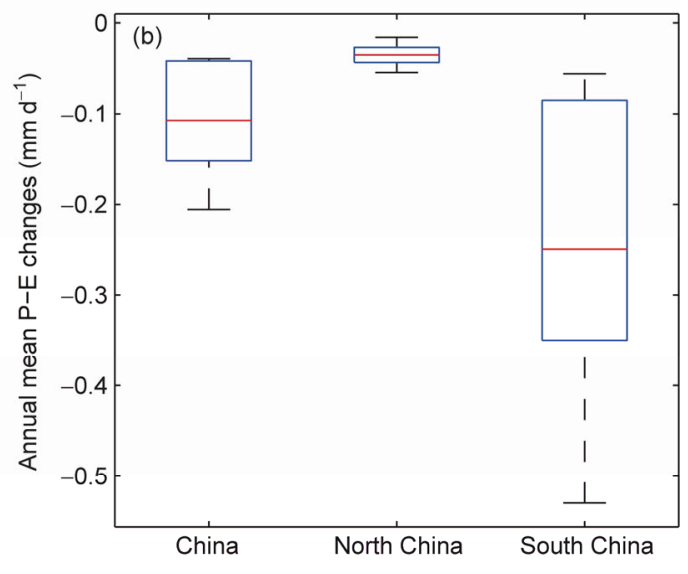

and winter by around $15 \%$ and $18 \%$ respectively and robust drops in soil moisture by $8 \%$ for all seasons. In contrast, in South China for all seasons, small increases in $\mathrm{P}$ and large increases in $\mathrm{E}$ were found to contribute to notable declines in both soil moisture and runoff. These changes of soil moisture in South China and North China combined contributed to the overall decrease of soil moisture for all seasons with the largest decrease in spring for the whole country. Overall, our result highlights the contrast hydrologic response to warming climate between North China and South China, although a similar magnitude of increase in $\mathrm{T}$ was found.

\subsection{Changes in mean and $\mathrm{CV}$ of runoff and soil mois- ture throughout the 21 st century at the regional scale}

Figure 7 shows the ensemble average change in annual mean and $\mathrm{CV}$ of runoff and soil moisture averaged over continental China. Generally, the projected changes are small in the early time horizon of the century, but they accelerate and maximize during the late 21 st century for the RCP8.5 scenario. Specifically, the ensemble of models indicates a persistent decrease of runoff and soil moisture by $15 \%$ and $8 \%$ respectively by the end of the 21 st century, implying that droughts will intensify in China throughout the 21 st century. Coincidentally, the changes of CV of runoff and soil moisture are characterized by long term positive trends, indicating larger interannual variability in the future. It should be noted that the CV change in soil moisture is somewhat higher than that of runoff, which suggests that soil moisture variability could be more sensitive to climate change than runoff when averaged over China. As indicated by the ensemble spread, considerable differences exist among the models for the projection of annual mean and $\mathrm{CV}$ changes in runoff and soil moisture throughout the 21st century. For example, the maximum standard deviation of the mean changes in runoff over all GCM scenarios in the time horizon is $10.20 \% / y e a r$, implying a relatively large 

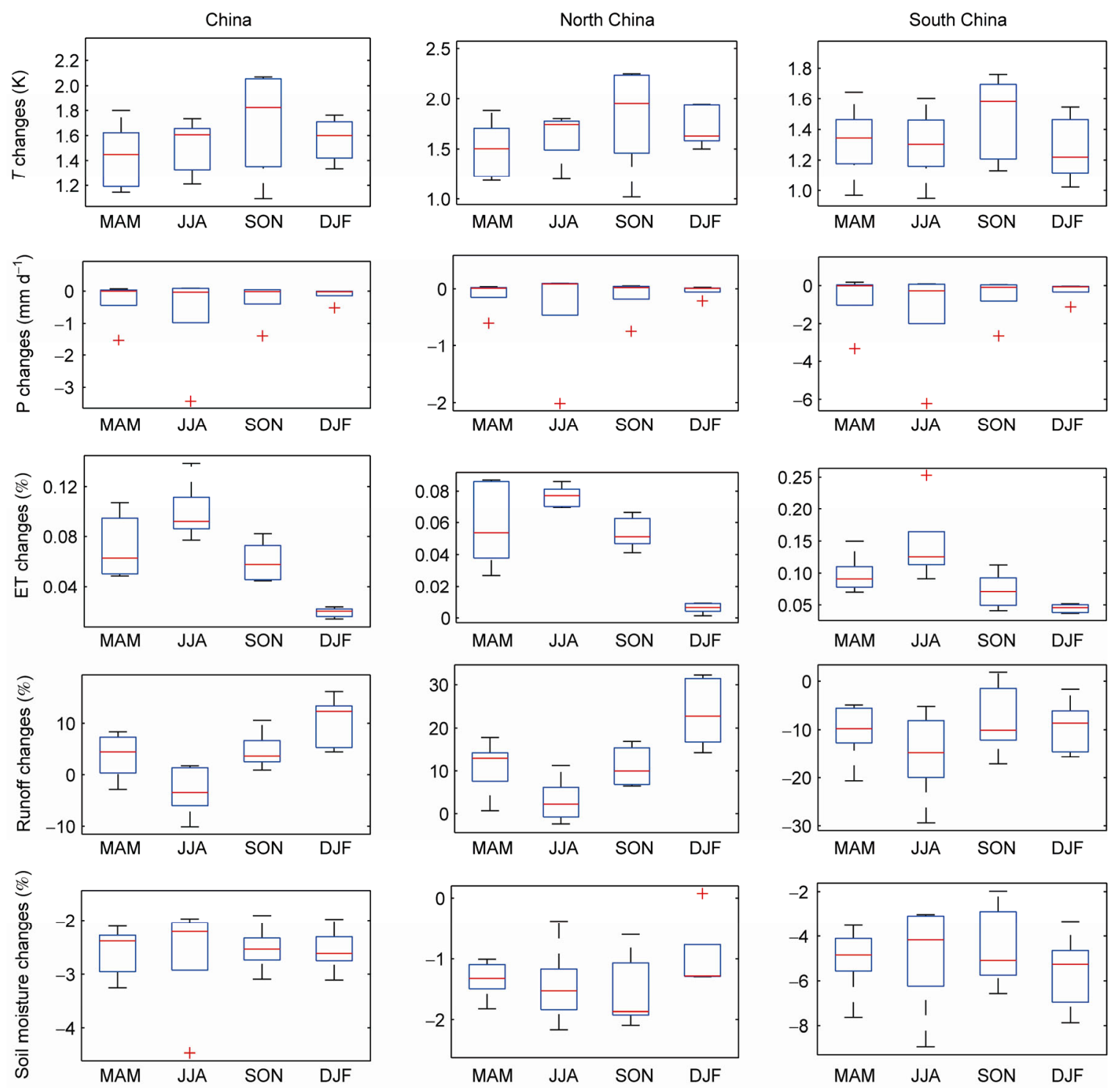

Figure 5 Changes by season in P, ET, runoff and soil moisture for 2071-2099 minus 1971-2000 for China, North China, and South China. The box edges illustrate the 25th and 75th percentile, the central mark is the median, and the whiskers mark the 5th and 95th percentiles. Note that MAM indicates the March, April, and May; JJA indicates June, July, and August; SON indicates September, October, and November; DJF indicates December, January, and February.

inter-model spread. Conversely, the scenarios agree well upon changes in annual mean soil moisture, with a maximum standard deviation of $1.92 \% / y e a r$. For the change of $\mathrm{CV}$ in runoff and soil moisture, the maximum large intermodel spread in the time horizon amounts to $9.39 \%$ and $17.10 \% / y e a r$ respectively, indicating a relatively low level of inter-model agreement on magnitude of projected $\mathrm{CV}$ change averaged over China, although most models projected increases in $\mathrm{CV}$ over time.

Figure 8 shows the monthly percentage changes in runoff and soil moisture for North China and South China. Similar to the annual mean changes as shown in Figure 7, the projected changes at the monthly scale are also small in the early time horizon of the century, but they accelerate and maximize during the late 21 st century for the RCP8.5 sce- nario. However, large seasonal variation and regional difference were found for the runoff changes. That is, a persistent increase of runoff greater than $25 \%$ over North China was found in winter and spring while a large decrease up to $-25 \%$ was found from April to September in the time horizon. In contrast, runoff changes over South China exhibit persistent and robust decreases up to $-20 \%$ for the all months except for September. Compared to the changes of runoff changes, soil moisture exhibits much more consistent seasonal response to future climate change. That is, decrease of soil moisture for both North China and South China was found for all the months throughout the 21st century. In addition, the magnitude of soil moisture $(-10 \%)$ is small relative to runoff changes for both North China and South China. 

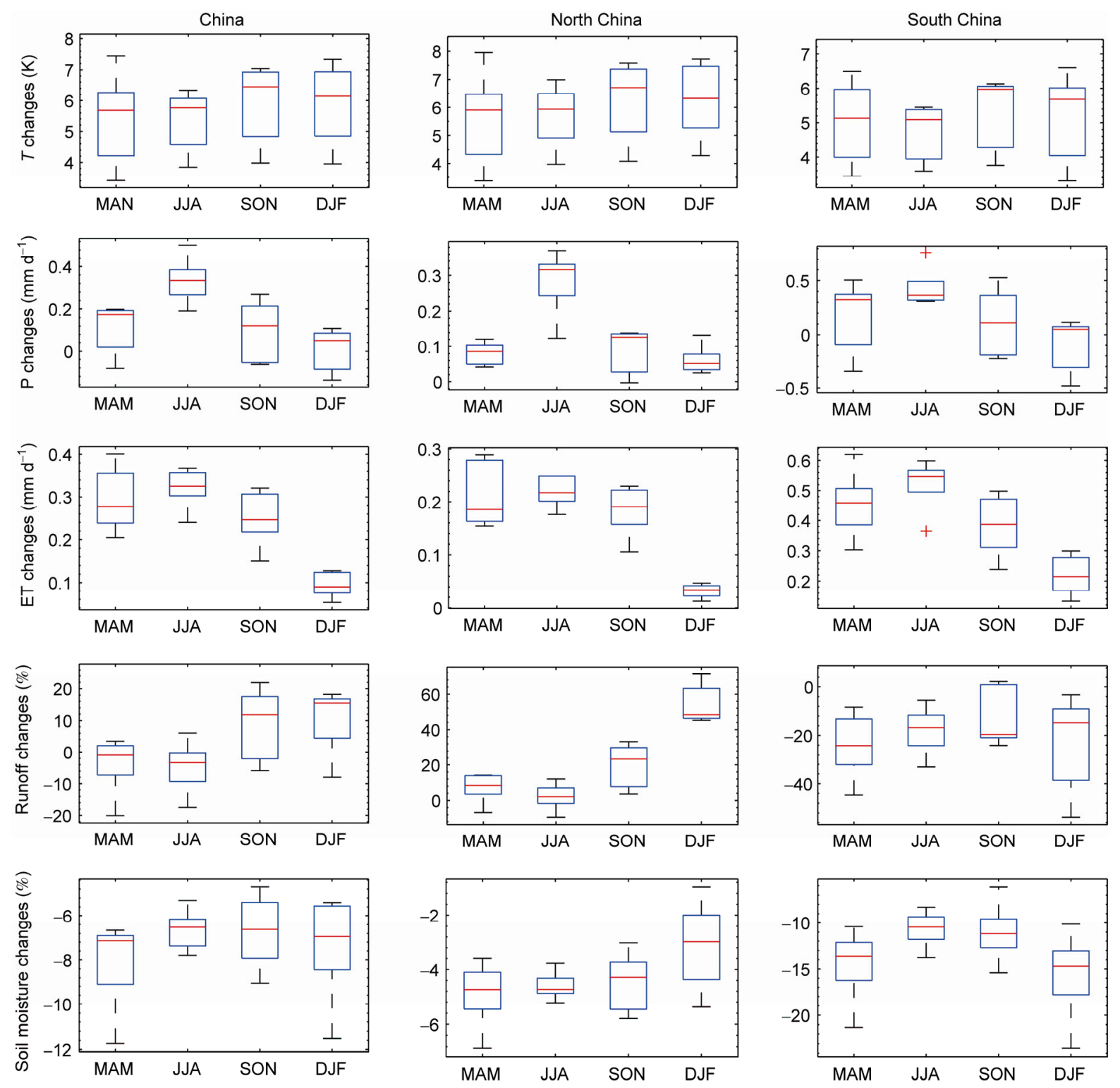

Figure 6 As in Figure 5 but for 2070-2099 minus 1971-2000.
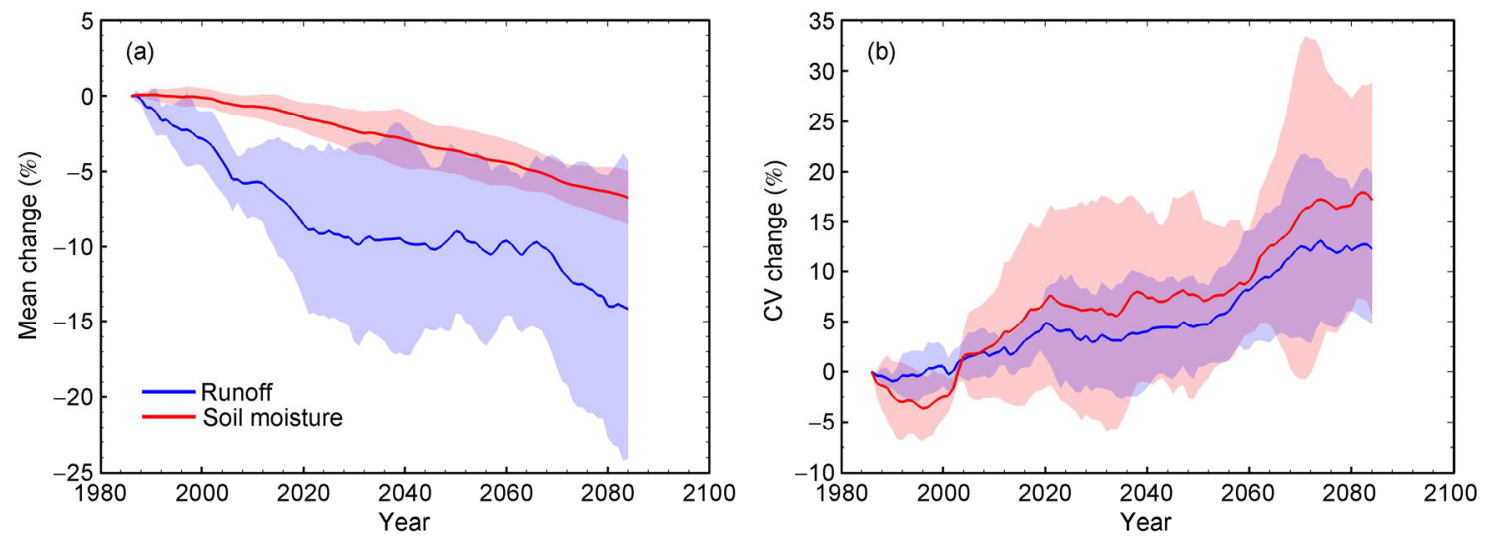

Figure 7 Multi-model ensemble average changes in annual (a) mean runoff (\%) and mean soil moisture (\%) and (b) runoff CV (\%) and soil moisture CV (\%) throughout the 21st century averaged over China under the RCP8.5 emission scenario. The changes are calculated for each 30 years running average in the time series with respect to 1971-2000. The shading denotes the one standard deviation. 

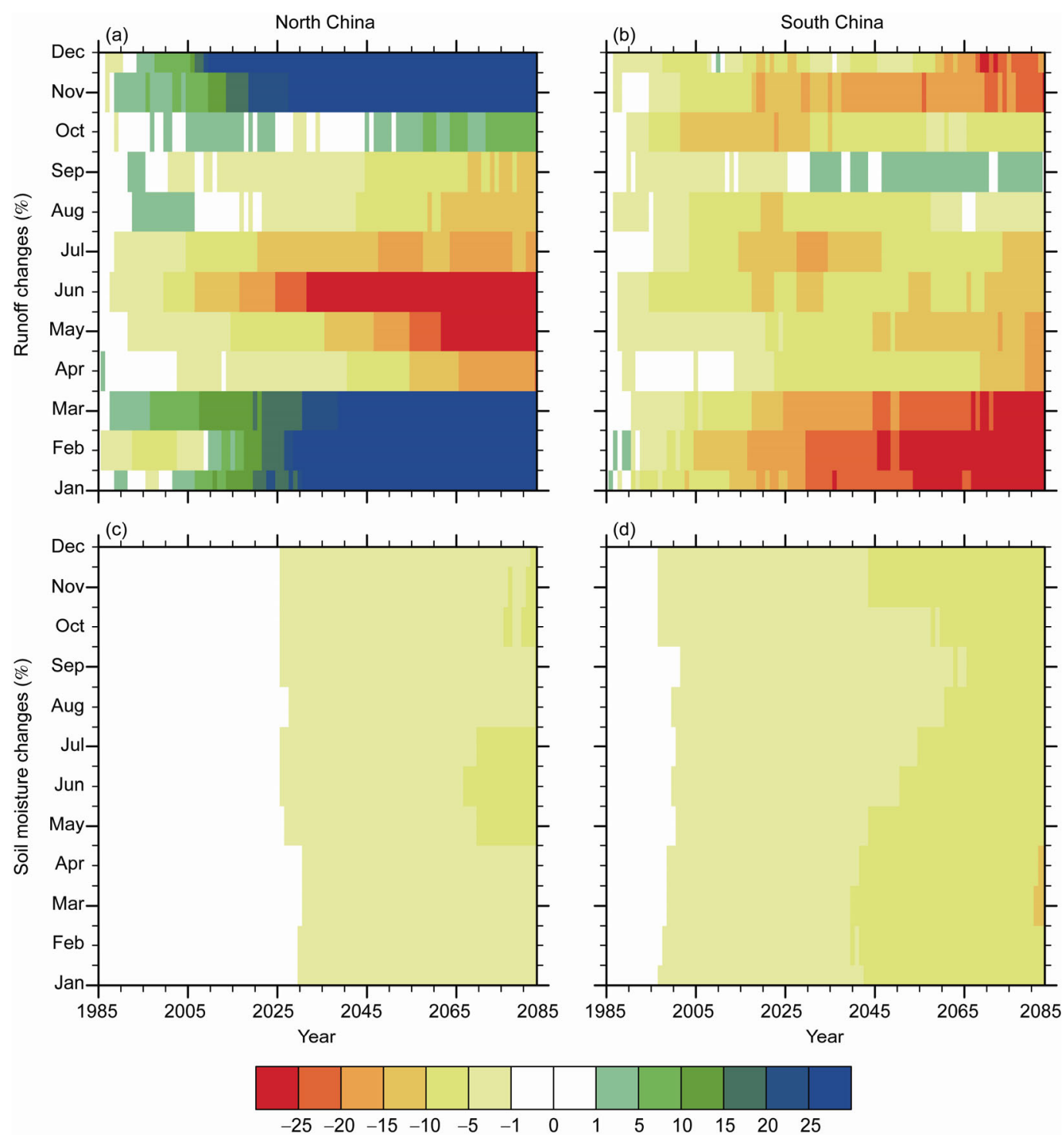

Figure 8 Ensemble average percent changes in monthly mean runoff (\%) for (a) North China, (b) South China and mean soil moisture (\%) for (c) North China, (d) South China throughout the 21 st century under the RCP8.5 emission scenario. The changes are calculated for each 30 period in the time series with respect to $1971-2000$.

As shown in Figure 9, the CV changes of runoff and soil moisture for North China and South China clearly show that large regional difference and seasonal variations for both runoff $\mathrm{CV}$ and soil moisture $\mathrm{CV}$ changes also exist between North China and South China. Runoff CV changes in South China increased persistently for all the months except April and November. In contrast, runoff $\mathrm{CV}$ changes in North China exhibit an overall decrease for most months. The regional contrast between North China and South China is even more significant for the soil moisture $\mathrm{CV}$ changes. That is, a large increase up to $25 \%$ of soil moisture CV was found for South China while a relatively small increase up to $10 \%$ was found for North China for the late 21 st century. It should be noted that a turning point for soil moisture $\mathrm{CV}$ changes in North China was found at the 2060s, indicating a decrease before the 2060s but an increase after the 2060s in the time horizon. Furthermore, the magnitude of percent changes in soil moisture CV in South China is much larger than changes in runoff $\mathrm{CV}$, suggesting that soil moisture $\mathrm{CV}$ could be more sensitive to future climate change than runoff $\mathrm{CV}$ in South China. Overall, our result highlights the contrast in mean and CV changes between North China and South China at the monthly scale.

\subsection{Changes in mean and $\mathrm{CV}$ of runoff and soil mois- ture throughout the 21 st century at the river basin scale}

To further look into the hydrologic response to future climate change at the river basin scale, Figure 10 shows the ensemble average of annual mean and variability changes in runoff and soil moisture over the ten river basins (Figure 1) across China. It is evident that the projected changes exhibit 

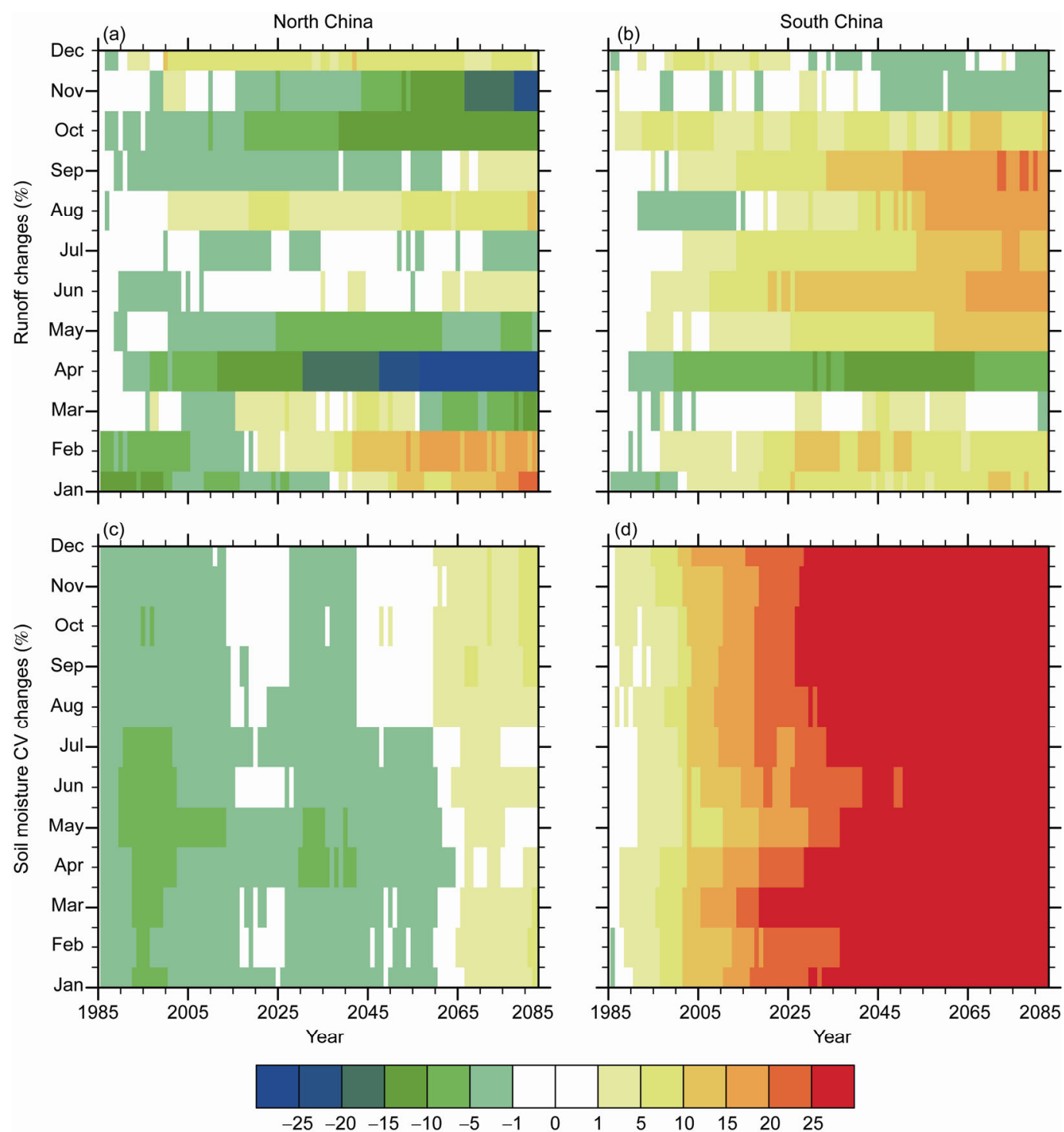

Figure 9 Ensemble average percent changes in monthly runoff CV (\%) for (a) North China, (b) South China and soil moisture CV (\%) for (c) North China, (d) South China throughout the 21st century under the RCP8.5 emission scenario. The changes are calculated for each 30 period in the time series with respect to 1971-2000.

obvious regional differences across China for annual mean runoff change (Figure 10(a)). Over North China, an increase of runoff by $15 \%$ is found for HR and no significant change for LR, while SR, YR, and NWR exhibit a persistent decrease trend throughout the 21 st century. Runoff in all the river basins over South China was projected to decrease persistently during the 21 st century, with the largest decrease up to $25 \%$ in YZR. The changes in runoff CV (Figure 10 (b)) differ among the river basins as well, showing marked increase for most river basins over South China and no long term trend for river basins over North China, except for YR with a persistent increase up to $25 \%$. These results thus suggest a general decrease of runoff reliability over South China indicated by the increasing interannual variability, where the largest increase of $\mathrm{CV}$ could reach $40 \%$ in SWR. For mean soil moisture (Figure 10(c)), we found a decrease for all ten river basins by the end of 21 st century, with varying magnitude between North and South China regions. Over North China, small decreases of annual mean soil moisture ranging from $2 \%$ to $4 \%$ are found for SR, LR, and HR while river basins over South China show a marked decrease up to $11 \%$. This implies that soil moisture induced droughts, or agricultural droughts, are projected to become more severe and extensive under future climate change for major river basins over South China. The changes in North China are relatively small because it is already an arid region with little soil moisture to support the increased evaporative demand in a warmer climate. Similar to changes of runoff CVs, CVs of soil moisture (Figure 10(d)) in river basins over North China are characterized by multi-decadal oscillations and non-evident long term trend, except for a decrease of $20 \%$ in NWR. However, the soil moisture CVs 

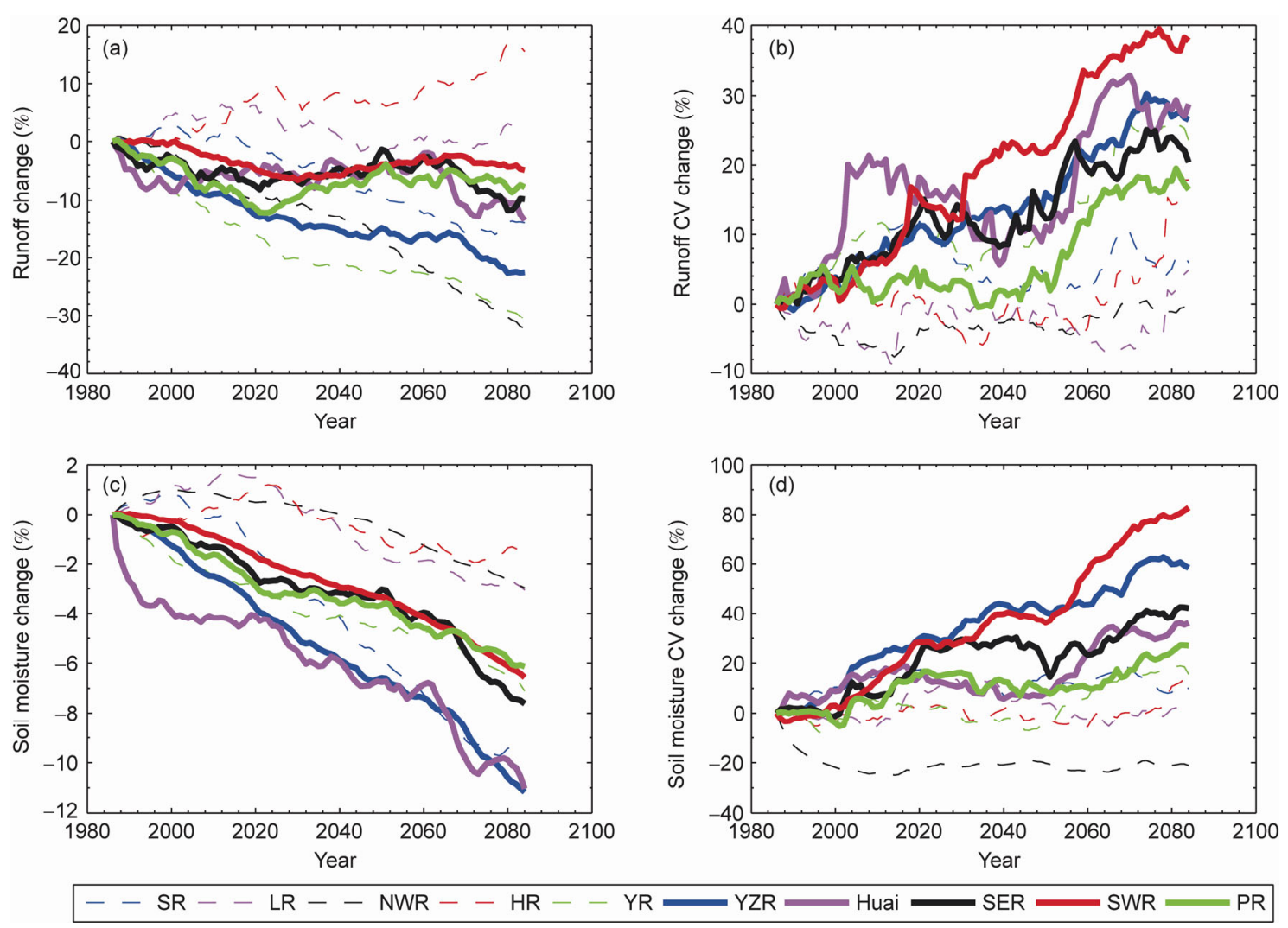

Figure 10 Ensemble average changes in annual (a) mean runoff (\%), (b) runoff CV (\%), (c) mean soil moisture (\%), and (d) soil moisture CV (\%) throughout the 21 st century for ten river basins over China under the RCP8.5 emission scenario. The changes are calculated for each 30 years running average in the time series with respect to 1971-2000. The river basins over North China are indicated by thin lines, while river basins over South China are indicated by thick lines.

show significant increases for the river basins over South China with the largest increase in SWR by up to $80 \%$. Overall, our results suggest that the projected decrease of annual mean runoff and soil moisture combined with increase of interannual variability may cause more risks for the water resource management (e.g., water security, water supply), especially across South China, and could be detrimental to the agriculture, industrial, and domestic water use in the future.

The temporal variations shown in Figure 10 provided an overall depiction of how hydrologic responses to climate change evolve throughout the 21 st century. However, the analysis showed interannual to decadal variations as well as some longer term trends. To summarize the trends of these changes, Figure 11 presents the ensemble average and standard deviation of the 21 st century trends in mean runoff and soil moisture and their CVs over all GCM scenarios for each river basin. These trends were calculated using the 30 years running averages from 1971 to 2099 to filter out shorter term fluctuations and are statistically significant at

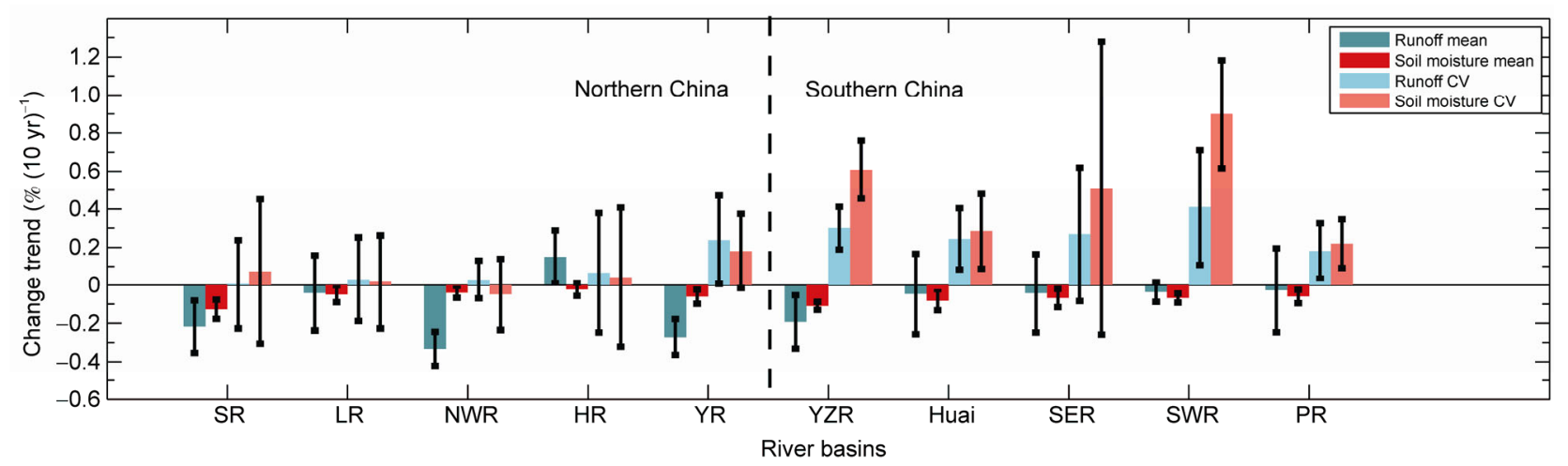

Figure 11 Ensemble average 21 st century trend $\left(\% \mathrm{yr}^{-1}\right)$ and Inter-Model standard deviation $\left(\% \mathrm{yr}^{-1}\right)$ of the trends for the changes of runoff mean, soil moisture mean, runoff $\mathrm{CV}$, and soil moisture $\mathrm{CV}$ in the 10 river basins across China. The error bar indicates one standard deviation. 
the $95 \%$ confidence level. For annual mean runoff, negative trends were found for all ten river basins except for HR, which shows a slight increase of $0.15 \%$ /year. The largest negative trends are found for NWR $(-0.33 \% /$ year $)$ and YR $(-0.31 \% / y e a r)$. The trends of ensemble average of mean soil moisture, however, are all negative and vary between $-0.02 \%$ and $-0.13 \% / y e a r$. In contrast, almost all basins show positive trends for CVs in the runoff and soil moisture, except for a slight decrease in soil moisture variability in NWR. The CV trends for both runoff and soil moisture are much larger in South China than in North China, indicating higher risks of floods or droughts in South China. This is confirmed by the higher values of soil moisture CVs compared to runoff CVs in South China, implying a greater variability of soil moisture in the future, consistent with the relationship between soil moisture and runoff variability shown in Figure 7(b). Noticeably, the largest trends in terms of CVs for runoff and soil moisture were both in SWR, with an increase by $0.41 \% /$ year and $0.90 \% / y e a r$ respectively. This suggests that SWR might be the region of the highest risk in terms of water resources security under projected future climate change, compared to other regions across China. Overall, both runoff and soil moisture show negative change trends in the future for most regions over China while the variability is expected to become much greater especially for South China.

\subsection{Possible mechanisms associated with the changes in mean and $\mathrm{CV}$ of runoff and soil moisture}

What are the main physical processes that might be associated with these changes of mean and variability for runoff and soil moisture under climate change? When looking at the corresponding ensemble average $\mathrm{P}$ and ET mean and variability changes in Figure 12, we found that positive trends of mean $\mathrm{P}$ and ET are for all river basins across China. Specifically, for the river basins over North China, a persistent and robust increase of annual mean $\mathrm{P}$ was found and was generally much larger than that over South China. A steady increase of annual mean ET was found for all ten river basins across China. However, the magnitude of annual mean ET change was much larger than that of annual mean $\mathrm{P}$, which contributed to the decrease of annual mean runoff and soil moisture for the major river basins across China (Figure 10(a), (c)). Moreover, compared to North China, a similar increase in ET in combination with smaller increase in $\mathrm{P}$ led to the much larger decrease in runoff and soil moisture for river basins over South China. For CVs, it is noted the CVs of $\mathrm{P}$ for the river basins over South China increase over time, but such changes were rarely found over
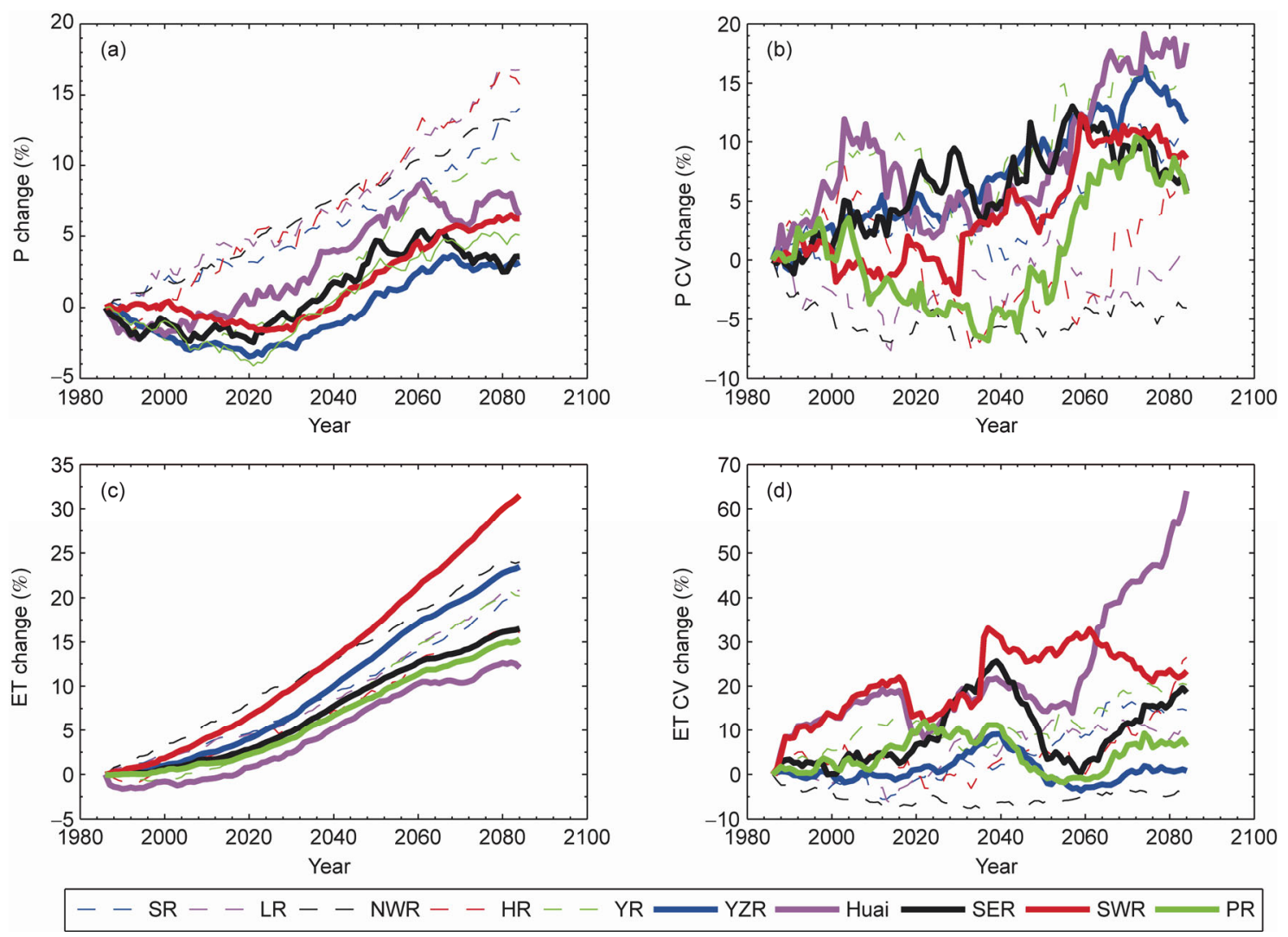

Figure 12 Ensemble average percent changes in annual (a) mean P (\%), (b) P CV (\%), (c) mean ET (\%), and (d) ET CV (\%) throughout the 21st century for ten river basins over China under the RCP8.5 emission scenario. The changes are calculated for each 30 years running average in the time series with respect to 1971-2000. The river basins over North China are indicated by thin lines, while river basins over South China are indicated by thick lines. 
North China, except for SR and YR where increases up to $15 \%$ and $10 \%$ respectively were found by the end of $21 \mathrm{st}$ century. Generally, the CVs of ET were characterized by multi-decadal oscillations with no evident trend throughout the 21 st century, except for the Huai and SWR river basins. This shows that generally the interannual variability of ET is not strongly forced by the interannual variability of $\mathrm{P}$. The relatively larger changes in CVs of P and ET led to the projected larger changes in CVs of runoff and soil moisture over South China than North China (Figure 10 (b), (d)). Also, negative trends for CVs of both $\mathrm{P}$ and ET are responsible for the decrease in CVs of runoff and soil moisture in NWR in North China. In summary, changes in the mean and variability of runoff and soil moisture, which are critical to water resource management, are associated primarily with combined effects of the corresponding P and ET changes from a water balance point of view.

From Figure 10(c), agricultural droughts, characterized by decreases in annual mean soil moisture, are expected to become more persistent under future climate change. Some observation-based studies have shown that changes in precipitation intensity could have more important impacts on the variation of summer soil moisture than changes in mean precipitation (Piao et al., 2009; Wu et al., 2012). To examine the effects of projected changes in precipitation frequency on soil moisture, Figure 13 shows the percent change in the annual number of daily precipitation events between the running mean of each future 30 year period and that of
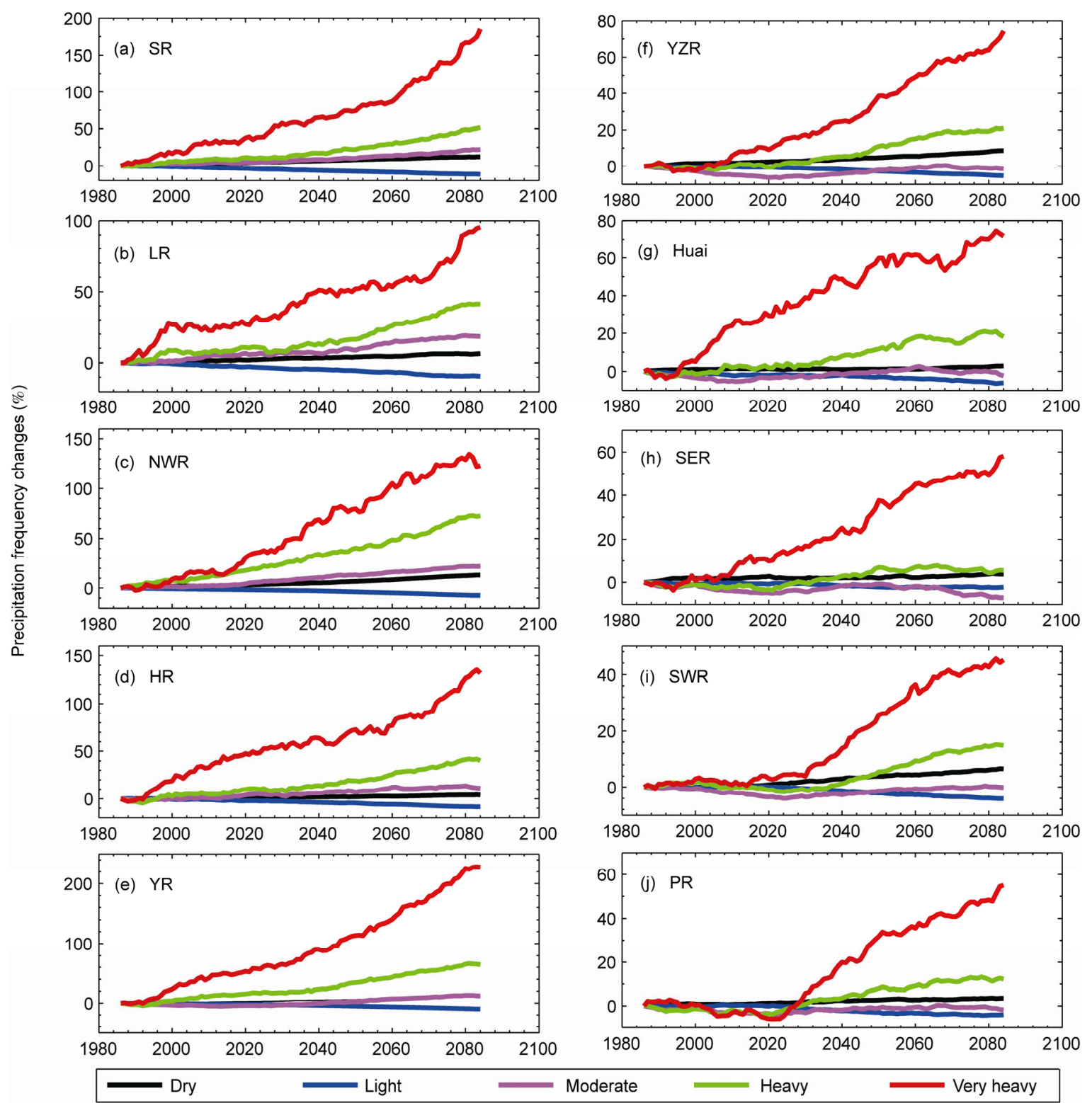

Figure 13 Ensemble average percent changes in the annual number of daily precipitation events for dry $(P=0)$, light $(0.1 \mathrm{~mm} \leqslant P<10 \mathrm{~mm})$, moderate $(10$ $\mathrm{mm} \leqslant P<25 \mathrm{~mm})$, heavy $(25 \mathrm{~mm} \leqslant P<50 \mathrm{~mm})$, and very heavy $(P \geqslant 50 \mathrm{~mm}$ ) precipitation throughout the 21 st century for ten river basins over China under the RCP8.5 emission scenario. The changes are calculated for each 30 years running average in the time series with respect to $1971-2000$. 
the reference period (1971-2000) for dry $(P=0)$, light $(0$ $\mathrm{mm} \leqslant P<10 \mathrm{~mm})$, moderate $(10 \mathrm{~mm} \leqslant P<25 \mathrm{~mm})$, heavy $(25 \mathrm{~mm} \leqslant P<50 \mathrm{~mm})$, and very heavy $(P \geqslant 50 \mathrm{~mm})$ precipitation events. The definition of these bands is to some extent qualitative and depends on the discriminating criteria of precipitation events. However, it is evident that there are more moderate, heavy, and very heavy daily precipitation events for all river basins over China throughout the $21 \mathrm{st}$ century while light precipitation changes little over time. Such a shift in the precipitation intensity leads to the increase of annual mean P shown in Figure 12(a). The increase of total precipitation caused by increase of heavy and very heavy precipitation events did not further lead to the increase of soil moisture as shown in Figure 10(c). This could be attributed partly to the persistent increase of dry days $(P=0)$, especially in river basins over South China. Our results suggest that the temporal changes in precipitation frequency and intensity could greatly affect soil moisture content. We emphasize the need to comprehensively evaluate the relationship between soil moisture and other precipitation characteristics (e.g., frequency and intensity) in addition to quantity, to provide a better understanding of agricultural droughts under climate change.

\section{Summary and conclusions}

By driving the VIC macroscale hydrologic model using the bias-corrected climatic data provided by the fast-track of ISI-MIP that aims at providing timely results for IPCC AR5, this study presents an updated examination of hydrologic responses to future climate change over China. Also, this study extends previous work by examining mean changes in $\mathrm{P}, \mathrm{ET}$, runoff and soil moisture and the corresponding interannual variability for all ten river basins across China throughout the 21st century. Physical interpretation of these changes is discussed, which motivates more comprehensive analysis to understanding the projected drying in the future. The main findings of this study are summarized in the following.

Spatially, surface water availability indicated by $\mathrm{P}-\mathrm{E}$ was projected to decrease by the end of the 21 st century especially for South China, although the same regions experienced increases in $\mathrm{P}$. This will reduce the existing uneven spatial structure of water resources over China, which is featured by the abundant water resource over South China and inadequate water resource over North China. The projected decrease in surface water availability can be attributed primarily to the larger fractional increase in ET per unit warming than the corresponding fractional changes in $\mathrm{P}$ per unit warming. Temporally, both annual mean runoff and soil moisture are projected to decrease persistently and robustly throughout the 21 st century while the corresponding interannual variability which affects the community the most, accelerates and maximizes during the late 21 st centu- ry for most river basins over China and for the country as a whole. In addition to the regional contrast between North China and South China, intra-seasonal variation was also large for the runoff mean and runoff $\mathrm{CV}$ changes, but small for the soil moisture mean and CV changes. Additionally, our study shows that soil moisture related droughts will increase in the future, especially for river basins over Southwest China. Overall, our results suggest that the decrease in surface water amounts combined with increasing interannual variability will cause more detrimental social and environmental risks across China, especially in Southwest China where exceptional drought disasters have already been frequently reported such as Yunnan in 2005, and Sichuan in 2009.

Relatively small increase in $\mathrm{P}$ combined with a much larger increase of ET in a warmer world contributed to the overall decrease in annual mean runoff and soil moisture for almost all river basins across China. Heavy and very heavy daily precipitation events were projected to increase greatly across China, which is consistent with previous studies reporting increases in heavy precipitation events in many regions around the world for the 20th century (Groisman et al., 2005; Kunkel et al., 2013). In addition to changes in mean precipitation, changes in precipitation frequency and intensity might also be associated with the significant decrease of soil moisture. Hence, more attention should be given to the precipitation intensity and frequency in assessing the climate change impacts on hydrology and water resource.

It is also important to recognize the uncertainties in evaluating climate change impacts on hydrology and water resources, including uncertainty stemming from future greenhouse gas emissions, GCMs, downscaling and bias correction methods and impact evaluation models (Haddeland et al., 2011; Hagemann et al., 2013). Specifically, numerous studies show that over-reliance on a single GCM could lead to an inappropriate projection or adaptation responses to climate changes. Our analysis indicates large differences among ensemble members driven by different GCMs (e.g., in Figures 3(a), 4(a)). By adopting arithmetic ensemble averages (AEMs) (Lambert and Boer, 2001), uncertainty from GCMs in impact analysis may be reduced to some extent. Uncertainty arising from hydrological model structure can also be large as model specific outputs can differ substantially among different hydrological models (Jiang et al., 2007; Gosling et al., 2011; Haddeland et al., 2011). Nevertheless, through model calibration against observation, Zhang et al. (2014) showed that the simulated streamflow and soil moisture after calibration show good agreement with reported statistics in general. By adopting the calibrated parameters from Zhang et al. (2014), the uncertainties from impact model (i.e., VIC) used in this study was to some extent reduced. However, addressing all these uncertainty sources such as greenhouse gas emissions, GCMs, downscaling and bias correction methods, and impact evaluation models has been challenging because no 
efficient way exists to handle all of them. These factors have been shown to play major roles in uncertainties in projecting hydrologic response to climate changes in the Colorado River Basin, which is marked by complex terrain and water balance dominated by snowmelt in the headwaters (Vano et al., 2013). To what extent these factors influence our analysis in China that encompasses diverse climate and hydrologic regimes is not clear and should be investigated in the future. Overall, through adopting multi-ensemble mean of GCMs and model calibration, uncertainties in this study were reduced as much as possible. In addition, through showing the specific GCM result (Figures 3(a), 4(a)) and box diagram/error bar (Figures 3(b), 4(b), 5-7 and 11), the uncertainty ranges or magnitude was provided for readers to better capture the useful information.

By providing regional analysis and comparison across all river basins in China, this study highlights important differences in hydrologic response between South China and North China at various temporal scales. Overall the reduction in runoff and soil moisture and the increase in interannual variability for both, especially in South China, should motivate more studies to understand the climate and hydrologic processes responsible for those changes and quantify uncertainties in the projections. We identified high-risk regions that could provide guidance for future climate change adaptation and mitigation strategies for water resource management (e.g., water allocation, water security, and agriculture irrigation) at the river basin, regional, and national scales.

The careful reviews and constructive comments/suggestions from two anonymous reviewers are gratefully acknowledged. This work was supported by the National Natural Science Foundation of China (Grant No. 41171031), National Basic Research Program of China (Grant No. 2012CB955403), and Hundred Talents Program of the Chinese Academy of Sciences. This work has been conducted under the framework of ISI-MIP. The ISIMIP Fast Track Project was funded by the German Federal Ministry of Education and Research (BMBF) (Grant No. O1LS1201A). Responsibility for the content of this publication lies with the authors. M Huang and LR Leung are supported by Office of Science of the U.S. Department of Energy through the Regional and Global Climate Modeling Program. PNNL is operated for the US DOE by Battelle Memorial Institute (Grant No. DE-AC05-76RL01830).

Arnell N W. 2003. Effects of IPCC SRES emissions scenarios on river runoff: A global perspective. Hydrol Earth Syst Sci, 7: 619-641

Canadell J G, Le Quéré C, Raupach M R, et al. 2007. Contributions to accelerating atmospheric $\mathrm{CO}_{2}$ growth from economic activity, carbon intensity, and efficiency of natural sinks. Proc Natl Acad Sci USA, 104: 18866-18870

Christensen N S, Wood A W, Voisin N, et al. 2004. Effects of climate change on the hydrology and water resources of the Colorado River Basin. Clim Change, 62: 337-363

Dai A. 2013. Increasing drought under global warming in observations and models. Nat Clim Change, 3: 52-58

Dan L, Ji J, Xie Z, et al. 2012. Hydrological projections of climate change scenarios over the $3 \mathrm{H}$ region of China: A VIC model assessment. J Geophys Res, 117: D11102

Durack P J, Wijffels S E, Matear R J. 2012. Ocean salinities reveal strong global water cycle intensification during 1950 to 2000. Science, 336:
$455-458$

Elliott J, Deryng D, Müller C, et al. 2014. Constraints and potentials of future irrigation water availability on agricultural production under climate change. Proc Natl Acad Sci USA, 111: 3239-3244

Easterling D R, Meehl G A, Parmesan C, et al. 2000a. Climate extremes: Observations, modeling, and impacts. Science, 289: 2068-2074

Easterling D R, Evans J L, Groisman P Y, et al. 2000b. Observed variability and trends in extreme climate events: A brief review. Bull Amer Meteorol Soc, 81: 417-425

Fujibe F, Yamazaki N, Kobayashi K. 2006. Long-term changes of heavy precipitation and dry weather in Japan (1901-2004). J Meteor Soc Jpn, 84: 1033-1046

Giorgi F, Bi X, Pal J S. 2004. Mean, interannual variability and trends in a regional climate change experiment over Europe. Part II: Future climate scenarios (2071-2100). Clim Dyn, 23: 839-858

Groisman P Y, Knight R W, Easterling D R, et al. 2005. Trends in intense precipitation in the climate record. J Clim, 18: 1326-1350

Gosling S N, Taylor R G, Arnell N W, et al. 2011. A comparative analysis of projected impacts of climate change on river runoff from global and catchment-scale hydrological models. Hydrol Earth Syst Sci, 15: 279-294

Guo S, Wang J, Xiong L, et al. 2002. A macro-scale and semi-distributed monthly water balance model to predict climate change impacts in China. J Hydrol, 268: 1-15

Haddeland I, Clark D B, Franssen W, et al. 2011. Multi-model estimate of the global terrestrial water balance: Setup and first results. J Hydrometeorol, 12: 869-884

Hamlet A F, Lettenmaier D P. 1999. Effects of climate change on hydrology and water resources in the Columbia River Basin. J Amer Water Resour Assoc, 35: 1597-1623

Hayhoe K, Wake C P, Huntington T G, et al. 2007. Past and future changes in climate and hydrological indicators in the US Northeast. Clim Dynam, 28: 381-407

Hempel S, Frieler K, Warszawski L, et al. 2013. A trend-preserving bias correction-The ISI-MIP approach. Earth Syst Dynam, 4: 219-236

Hagemann S, Chen C, Clark D B, et al. 2013. Climate change impact on available water resources obtained using multiple global climate and hydrology models. Earth Syst Dynam, 4: 129-144

Jiang T, Chen Y, Xu C, et al. 2007. Comparison of hydrological impacts of climate change simulated by six hydrological models in the Dongjiang Basin, South China. J Hydrol, 336: 316-333

Katz R W, Brown B G. 1992. Extreme events in a changing climate: Variability is more important than averages. Clim Change, 21: 289-302

Kranz N, Menniken T, Hinkel J. 2010. Climate change adaptation strategies in the Mekong and Orange-Senqu basins: What determines the state-of-play? Environ Sci Policy, 13: 648-659

Kunkel K E, Thomas R K, Harold B, et al. 2013. Monitoring and understanding trends in extreme storms: State of knowledge. Bull Amer Meteorol Soc, 94: 499-514

Lambert S J, Boer G J. 2001. CMIP1 evaluation and intercomparison of coupled climate models. Clim Dynam, 17: 83-106

Liang X, Lettenmaier D P, Wood E F, et al. 1994. A simple hydrologically based model of land surface water and energy fluxes for GSMs. J Geophys Res, 99: 14415-14428

Liang X, Lettenmaier D P, Wood E F. 1996. One-dimensional statistical dynamic representation of subgrid spatial variability of precipitation in the Two-Layer Variable Infiltration Capacity model. J Geophys Res, 101: 21403-21422

Li L, Hao Z C, Wang J H, et al. 2008. Impact of future climate change on runoff in the head region of the Yellow River. J Hydrol Eng, 13: 347-354

Li Z, Liu W Z, Zhang X C, et al. 2010. Assessing and regulating the impacts of climate change on water resources in the Heihe watershed on the Loess Plateau of China. Sci China Earth Sci, 53: 710-720

Maurer E P. 2007. Uncertainty in hydrologic impacts of climate change in the Sierra Nevada, California under two emissions scenarios. Clim Change, 82: 309-325

Moss R H, Edmonds J A, Hibbard K A, et al. 2010. The next generation of scenarios for climate change research and assessment. Nature, 463: 
$747-756$

Mote P, Brekke L, Duffy P B, et al. 2011. Guidelines for constructing climate scenarios. Eos Trans AGU, 92: 257

Nijssen B, Lettenmaier D P, Liang X, et al. 1997. Streamflow simulation for continental-scale river basins. Water Resour Res, 33: 711-724

Nijssen B, Schnur R, Lettenmaier D P. 2001. Global retrospective estimation of soil moisture using the Variable Infiltration Capacity land surface model, 1980-93. J Clim, 14: 1790-1808

O'Gorman P A O, Schneider T. 2009. The physical basis for increases in precipitation extremes in simulations of 21 st-century climate change. Proc Natl Acad Sci USA, 106: 14773-14777

Piao S, Yin L, Wang X, et al. 2009. Summer soil moisture regulated by precipitation frequency in China. Environ Res Lett, 4: 044012

Piao S L, Ciais P, Huang Y, et al. 2010. The impacts of climate change on water resources and agriculture in China. Nature, 467: 43-51

Pierce D W, Barnett T P, Santer B D, et al. 2009. Selecting global climate models for regional climate change studies. Proc Natl Acad Sci USA, 106: 8441-8446

Piontek F, Müller C, Thomas A M P, et al. 2014. Multi-sectoral climate impact hotspots in a warming world. Proc Natl Acad Sci USA, 111: 3233-3238

Portmann F T, Döll P, Eisner S, et al. 2013. Impact of climate change on renewable groundwater resources: Assessing the benefits of avoided greenhouse gas emissions using selected CMIP5 climate projections. Environ Res Lett, 8: 024023

Qiu J. 2010. China drought highlights future climate threats. Nature, 465: 142-143

Reichler T, Kim J. 2008. How well do coupled models simulate today's climate? Bull Amer Meteorol Soc, 89: 303-311

Rahmstorf S, Coumou D. 2011. Increase of extreme events in a warming world. Proc Natl Acad Sci USA, 108: 17905-17909

Räisänen J. 2002. $\mathrm{CO}_{2}$-induced changes in interannual temperature and precipitation variability in 19 CMIP2 experiments. J Clim, 15: 2395-2411

Robock A, Vinnikov K Y, Srinivasan G, et al. 2000. The global soil moisture data bank. Bull Amer Meteorol Soc, 81: 1281-1299

Rogelj J, Meinshausen M, Knutti R. 2012. Global warming under old and new scenarios using IPCC climate sensitivity range estimates. Nat Clim Change, 2: 248-253
Schar C, Vidale P L, Luthi D, et al. 2004. The role of increasing temperature variability in European summer heatwaves. Nature, 427: 332-336

Schewe J, Heinke J, Gerten D, et al. 2014. Multimodel assessment of water scarcity under climate change. Proc Natl Acad Sci USA, 111: 3249-3250

Tang Q, Lettenmaier D P. 2012. 21st century runoff sensitivities of major global river basins. Geophys Res Lett, 39: L06403

Vano J A, Udall B, Cayan D R, et al. 2013. Understanding uncertainties in future Colorado river streamflow. Bull Amer Meteorol Soc, 95: 59-78

Wada Y, Wisser D, Eisner S, et al. 2013. Multi-model projections and uncertainties of irrigation water demand under climate change. Geophys Res Lett, 40: 4626-4632

Wang G Q, Zhang J Y, Jin J L, et al. 2012. Assessing water resources in China using PRECIS projections and a VIC model. Hydrol Earth Syst Sci, 16: 231-240

Wu C, Chen J, Pumpanen J, et al. 2012. An underestimated role of precipitation frequency in regulating summer soil moisture. Environ Res Lett, 7: 024011

Xu Y, Zhang X, Tian Y. 2012. Impact of climate change on 24-h design rainfall depth estimation in Qiantang River Basin, East China. Hydrol Process, 26: 4067-4077

Xu Z, Zhao F, Li J. 2009. Response of runoff to climate change in the headwater catchment of the Yellow River basin. Quatern Int, 208: 62-75

Yao C, Yang S, Qian W, et al. 2008. Regional summer precipitation events in Asia and their changes in the past decades. J Geophys Res, 113: D17107

Yang C, Yu Z, Hao Z, et al. 2012. Impact of climate change on flood and drought events in Huaihe River Basin, China. Hydrol Res, 43: 14-22

Zeng X, Kundzewicz Z W, Zhou J, et al. 2012. Discharge projection in the Yangtze River basin under different emission scenarios based on the artificial neural networks. Quatern Int, 282: 113-121

Zhang X, Tang Q, Pan M, et al. 2013. A long-term land surface hydrologic fluxes and states dataset for China. J Hydrometeor, 15: 957-972

Zhang J, Wang G, Pagano T C, et al. 2013. Using hydrologic simulation to explore the impacts of climate change on runoff in the Huaihe River Basin of China. J Hydrol Eng, 18: 1393-1399

Zhai P, Zhang X, Wan H, et al. 2005. Trends in total precipitation and frequency of daily precipitation extremes over China. J Clim, 18: $1096-1108$ 